Primljen / Received: 2.9.2016.

Ispravljen / Corrected: 4.3.2017.

Prihvaćen / Accepted: 10.3.2017.

Dostupno online / Available online: 10.6.2017.

\section{Prediction of properties of recycled aggregate concrete}

Authors:

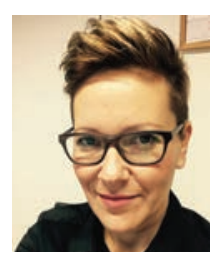

Assist.Prof. Ivana Miličević, PhD. CE J.J. Strossmayer University in Osijek Faculty of Civil Engineering ivana.milicevic@gfos.hr

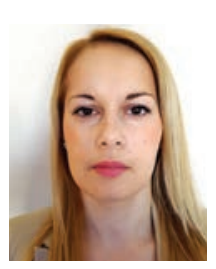

Assist.Prof. Tanja Kalman Šipoš, PhD. CE

J.J. Strossmayer University in Osijek

Faculty of Civil Engineering

tkalman@gfos.hr
Ivana Miličević, Tanja Kalman Šipoš

Original scientific paper

\section{Prediction of properties of recycled aggregate concrete}

Use of recycled materials as replacement for natural aggregate in concrete is important considering the environmentally beneficial aspect of its re-use. Relations between concrete components and concrete properties cannot be presented based on mathematical formulas only. Consequently, artificial neural networks and regression techniques were applied to analyse experimental results obtained according to previous experimental design. It was established that both techniques enable highly reliable modelling of concrete properties based on its components.

Key words:

neural network, mathematical model, crushed tile, crushed brick, concrete properties

Izvorni znanstveni rad

\section{Ivana Miličević, Tanja Kalman Šipoš}

\section{Predvidanje svojstava betona od recikliranih agregata}

Upotreba recikliranih materijala kao zamjene prirodnom agregatu u betonu značajna je iz ekološki prihvatljivog aspekta njegove ponovne upotrebe. Veza između komponenti betona i njegovih svojstava ne može biti prikazana samo na osnovi matematičkih formula. Prema tome, primijenjene su umjetne neuronske mreže i regresijska analiza eksperimentalnih rezultata postignutih planiranjem eksperimenta. Dokazano je da obje primijenjene tehnike omogućuju visoku pouzdanost za modeliranje svojstava betona na osnovi njegovih komponenti.

Ključne riječi:

neuronska mreža, matematički model, drobljeni crijep, drobljena opeka, svojstva betona

\section{Ivana Miličević, Tanja Kalman Šipoš}

Wissenschaftlicher Originalbeitrag

\section{Vorhersage der Eigenschaften von Recyclingbeton}

Die Anwendung von recyceltem Material als Ersatz natürlicher Gesteinskörnung für Beton ist aufgrund des ökologisch akzeptablen Aspekts der Wiederverwertung bedeutend. Der Zusammenhang zwischen den Betonkomponenten und seinen Eigenschaften kann nicht ausschließlich mittels mathematischer Formeln dargestellt werden. Daher wurden künstliche neuronale Netze und eine Regressionsanalyse experimenteller Resultate im Bezug zur Planung des Experiments angewandt. Es wurde bewiesen, dass beide eingesetzten Techniken eine hohe Zuverlässigkeit bei der Modellierung von Betoneigenschaften aufgrund seiner Komponenten aufweisen.

\section{Schlüsselwörter:}

neuronales Netz, mathematisches Modell, zerkleinerte Dachziegel, zerkleinerte Ziegelsteine, Betoneigenschaften 


\section{Introduction}

An optimum use of limited natural resources is essential to ensure proper environmental protection. Considering that aggregates constitute about 60 to 75 percent of the total volume of concrete, any reduction in natural aggregate consumption will have significant positive influence on the environment [1]. In addition, the use of recycled materials as replacement for natural aggregate in concrete is the current imperative for environmentally friendly re-use of such materials. A type of recycled material that can be used as aggregate in concrete is the waste generated during production of ceramic materials, such as clay bricks and clay roof tiles. Although most of this waste is already being incorporated as raw material in new ceramic products, some of it, and especially waste produced by construction industry, is deposited in landfills. Thus the Recycled Aggregate Concrete (RAC) has become an interesting environmentally friendly material with certain unknown properties that need to be explored in full detail. Debieb and Kenai [2] used coarse and fine crushed bricks and reported a $20 \%$ to 30 $\%$ decrease in compressive strength of RAC concrete depending on the degree of substitution. Cachim [1] shows that crushed bricks can be used as natural aggregate with substitution of up to $15 \%$, without any reduction in the compressive strength of concrete. However, reduction in compressive strength (up to 20 $\%$, depending on the type of brick) was registered when $30 \%$ of natural aggregate was replaced with crushed bricks.

In this respect, it can be concluded there is a need for reliable prediction of the properties of concrete containing crushed clay brick and roof tile (CBT) as partial replacement of natural aggregate.

As the behaviour and properties of CBT have not as yet been fully defined, some additional studies should be made to determine their behavioural pattern. Nevertheless, extensive testing involves certain quantities of material, adequate time, and funding. Thus to improve knowledge about behaviour of CBT aggregate in concrete, and to reduce the cost and time required for testing, models with behaviour simulation capabilities were investigated using the input and output data from experimental study [3].

One of the modelling techniques that are used for simulating behaviour of concrete containing recycled material are Artificial Neural Networks (ANN), which have over time become an important research tool [4-6]. However, an effectiveness and applicability of reported relationships between concrete components and properties still remain questionable. There is a need for development of accurate and convincing prediction models that can save time and costs by providing reliable data without experimental testing. This paper provides a comprehensive study that involves the use of advanced neural networks and mathematical modelling (MM) as a means to predict material properties of concrete containing crushed clay brick and roof tile (CBT) as partial replacement of natural aggregate.
In addition, an attempt was also made to determine importance of each output variable using sensitivity analysis. Principal objectives of this study are:

- to explore the possibility of predicting material properties with the limited number of inputs, i.e., by using mandatory parameters, based on the application of the ANN and mathematical modelling.

- to develop models for predicting material properties, and understand the performance and influence of each additional input parameter on output data (sensitivity analysis).

\section{Experimental design of RAC mixtures}

\subsection{Types of experimental design}

When contemplating optimization of RAC mixtures, it is necessary to obtain their basic material properties for varied quantities of the concrete components that are supposed to be significant for concrete mixture properties. Experimental design is applied so that experiments can be defined in an organized and clear manner, to enable statistical analysis of resulting data, as practiced in various areas of engineering [7-9]. The purpose of statistical analysis is to evaluate the second-order model for individual concrete properties.

This part of research aims to predict properties of concrete containing crushed brick and roof tile (CBT) with mathematical model using the response surface method to obtain the secondorder model:

$O i-M=f\left(F_{1}, F_{2}, \ldots, F_{k}\right)=\beta_{0}+\sum_{i=1}^{k} F_{i}+\sum_{i=1}^{k} \beta_{i i} F_{i}^{2}+\sum_{i<j} \sum_{j=2} \beta_{i j} F_{i} F_{j}$

where response marked as Oi-M is a mathematically obtained concrete characteristic, $F$ factors are the values of RAC components, while b coefficients must be calculated so as to correspond as much as possible to experimental response values. After that, the concrete mixtures will be optimized using a multi-criteria decision-making procedure by overlaying the contour plots based on second-order models of particular concrete properties.

Two effective experimental design procedures are presented: the central composite design (CCD) and the Box-Behnken (BB) design. Neither of these design procedures requires a lot of observations, i.e. only general data are needed to estimate the second-order effects of the response surface, using three or five levels for each factor, but not using all combinations of levels. Both procedures are rotatable (all points situated at equal distance from the centre in any direction have equal variance of prediction) at least approximately.

The central composite design (CCD) is an experimental design based on the response surface methodology for generation of a second-order regression equation. It consists of a factorial design (the corners of a cube) together with central and axial points (Figure 1). The type of CCD that will be applied for the 
design of experiments (the position of central and axial points) is determined by the number of factors $(k)$ and by the number of required properties. Basic types of central composite design are:

- Circumscribed (CCC) - requires five levels $(-\alpha,-1,0,1, \alpha)$

- Inscribed (CCI) - requires five levels $(-1,-1 / \alpha, 0,1 / \alpha, 1)$

- Faced (CCF) - requires three levels $(-1,0,1)$

where the distance of axial points $\alpha$ can be determined according to Montgomery [10]:

$\alpha=\left[2^{k}\right]^{\frac{1}{4}}$

Three types of central composite designs are (CCD) shown in Figure 1. It can be noted that the CCC explores the largest and the CCl explores the smallest process space. Both the CCC and $\mathrm{CCl}$ have rotatable designs, which is not the case for the CCF. In the CCC design, the design points are characterized by a circle circumscribed around the factorial square, [11].

The Box-Behnken (BB) design can be useful when the intent is to avoid extreme combinations of factors. The BB design (Figure 2 ) is rotatable, requires $2 k(k-1)+1$ experiments and three level factors $(-1,0,+1)$. standard factor levels - $\alpha$ and $\alpha$ for circumscribed CCD only. For all other designs, top and bottom limits correspond to standard factor levels -1 and 1, respectively. All other factor levels can easily be calculated using the defined top and bottom factor levels.

The top and bottom limits in Table 1 are chosen based on previously conducted experimental investigations and according to literature recommendations [12-16]. According to Hansen [17], cement content in concrete with CBT as aggregate can be increased by up to $20 \%$ as compared to concrete with natural aggregate. Also, it depends on the type and composition of CBT used as aggregate.

Table 1. Range of basic components of RAC concrete (factors)

\begin{tabular}{|c|c|c|c|}
\hline Factor & Concrete components & Lower limit & Upper limit \\
\hline F1 & Cement [kg] & 300 & 500 \\
\hline F2 & w/c ratio & 0,15 & 0,60 \\
\hline F3 & Concrete additive [\%] & 0 & 1 \\
\hline F4 & CB 0-4 mm [\%] & 0 & 50 \\
\hline F5 & CB 4-16 mm [\%] & 0 & 50 \\
\hline F6 & CT 0-4 mm [\%] & 0 & 50 \\
\hline F7 & CT 4-16 mm [\%] & 0 & 50 \\
\hline
\end{tabular}
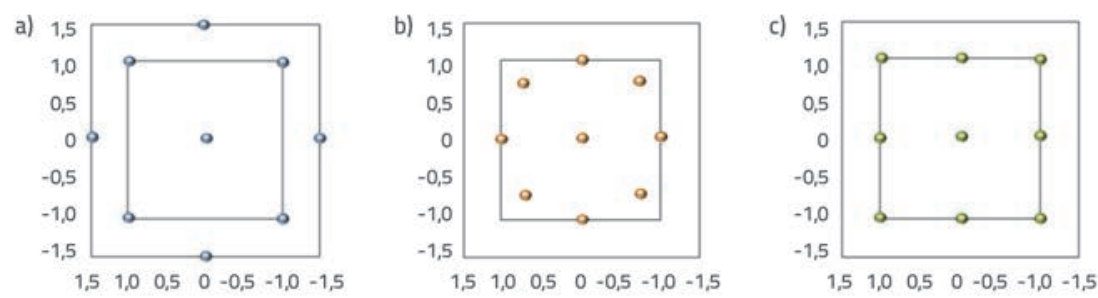

Figure 1. Example of central composite designs (k = 2): : a) CCD; b) CCl; c) CCF

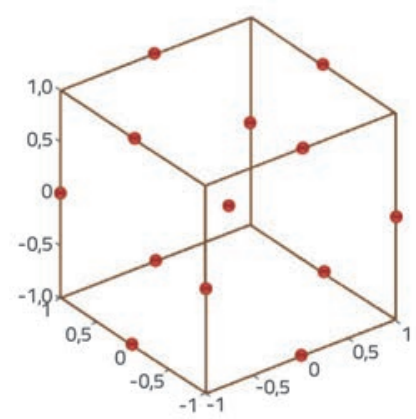

Figure 2. Example of Box-Behnken design ( $k=3)$

\section{Application of experimental design}

Seven basic RAC components, important for optimisation and used in experimental design, are: cement, water/cement ratio, water reducing admixture, percentage of crushed roof tile (CT), and percentage of recycled aggregate made of crushed brick (CB) fractions $0-4 \mathrm{~mm}$ and $4-16 \mathrm{~mm}$. The variation range of each factor is shown in Table 1. The top and bottom limits correspond to
Natural aggregate dolomite (NA) is also used in mixtures, but its percentage depends on the percentage of CB and CT aggregate:

$P A(\%)=100 \%-D C(\%)-D O(\%)$

and therefore NA is not a factor. Furthermore, the percentage of $\mathrm{CB}$ and CT aggregate must be limited as follows:

$D O(\%)+D C(\%) \leq 100 \%$

The central composite design obviously has a significantly higher number of experiments as compared to Box-Behnken (BB) design, Table 2.

Table 2. Number of experiments

\begin{tabular}{|c|c|c|c|c|}
\hline Types of planning & CCD & CCC & CCF & BB \\
\hline Number of experiments & 143 & 143 & 143 & 62 \\
\hline
\end{tabular}

As mentioned in Miličević et al. [18], the cost of one mixture amounts to approximately $€ 6125$. A simple calculation reveals that the central composite experimental design for seven factors is not cost and time effective. Therefore, the Box-Behnken experimental design will be considered for determining an optimum concrete mixture containing recycled aggregate. The experimental investigation defined by Box-Behnken design is shown in Miličević et al. [19]. 


\section{Prediction of concrete properties}

\subsection{Experimental results}

Concrete specimens are tested in accordance with HRN EN 12390-3:2009, HRN EN 12390-5:2009, HRN EN 123907:2009, and HRN U.M1.025:1982. Figures 3 and 4 show experimental results for density (01), compressive strength (02), flexural strength (03) and modulus of elasticity (04). Experimental testing of concrete properties 01 to 04 was conducted at the age of 56 days.

\subsection{Properties of concrete obtained by mathematical model}

Coefficients $\beta$ needed for Oi-M response in Eq. (1) were calculated using the regression analysis in Matlab, whose algorithm is based on the QR matrix decomposition. The condition (5) should be fulfilled to perform the algorithm successfully.

\section{number of coefficients $\leq$ number of experiments $=\mathbf{6 2}$}

The second-order model (1) contains 36 model parameters and so the condition (5) is fulfilled. Table 3 shows coefficients $\beta$ calculated for every concrete property selected (01-M to 04M).

Results of RAC concrete properties with CBT aggregate for mathematical model are presented in Section 5 and compared to the ANN modelling results.

\subsection{Properties of concrete predicted with artificial neural network}

According to Haykin [21], Artificial Neural Networks (ANN) are a massive parallel architecture that can be used to solve and find answers to demanding problems using simple mutually dependent processing elements (artificial neurons). Essentially, they are analogous to natural neurons in the brain, which consist of many simple interconnected elements arranged in several layers. An ANN has considerable capabilities in data processing and learning and can therefore be an effective tool for engineering applications.

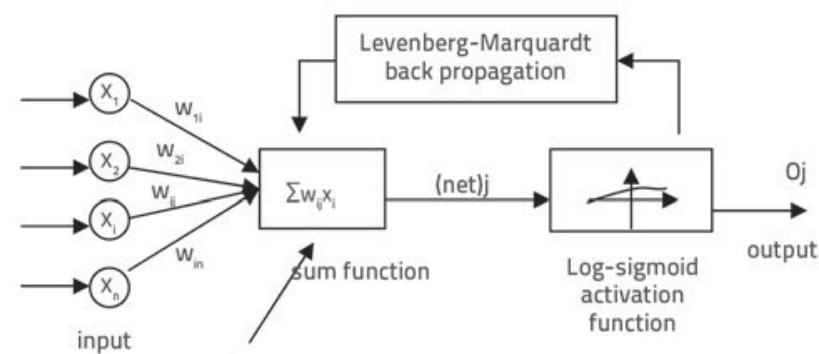

(b)

Figure 5. Architecture of neural network

An artificial neuron (Figure 5) consists of five basic parts: input neurons, weights, sum function, activation function, and output neurons. Input neurons are the basic input receiving data at the

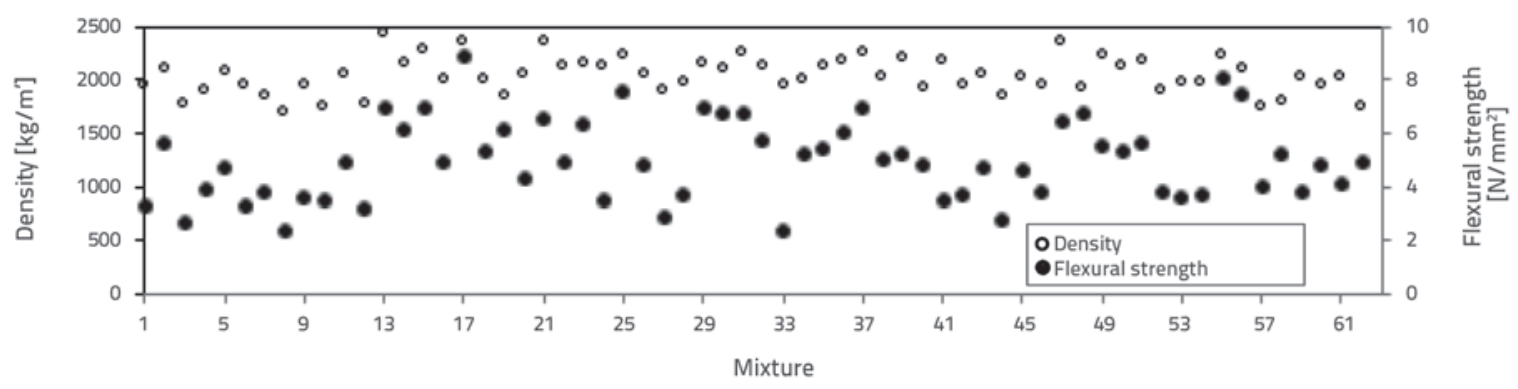

Figure 3. Density and flexural strength of hardened concrete

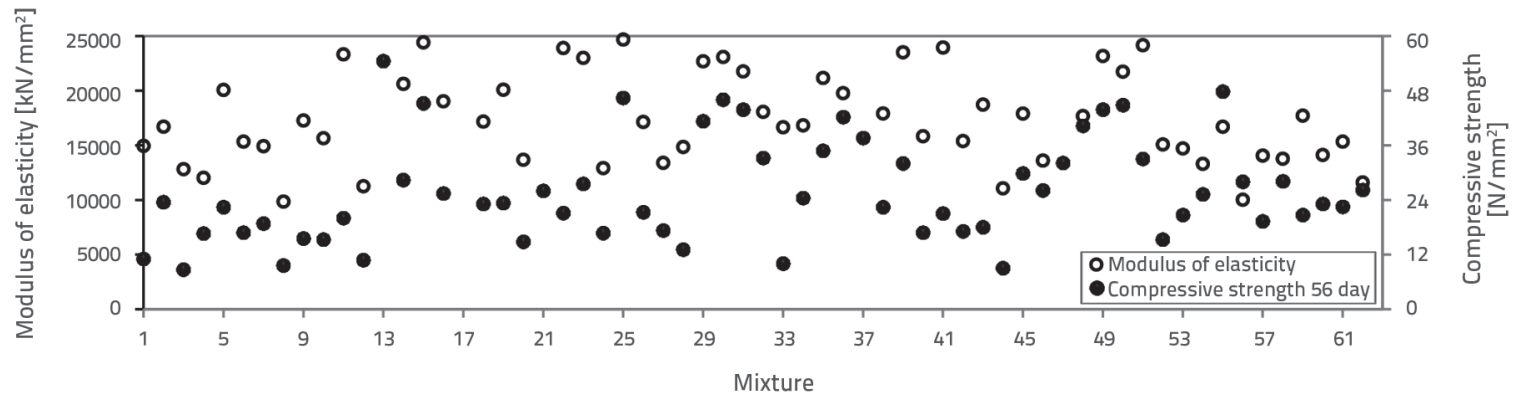

Figure 4. Properties of hardened concrete at $\mathbf{5 6}$ days 
Table 3. Coefficients $\beta$

\begin{tabular}{|c|c|c|c|c|c|c|c|c|c|}
\hline$\beta$ & $\mathbf{0 1 - M}$ & $\mathbf{0 2 - M}$ & $\mathbf{0 3 - M}$ & $\mathbf{0 4 - M}$ & $\beta$ & $\mathbf{0 1 - M}$ & $\mathbf{0 2 - M}$ & $\mathbf{0 3 - M}$ & $\mathbf{0 4 - M}$ \\
\hline$\beta_{0}$ & 2038.40 & 23.30 & 2.19 & 14436.00 & $\beta_{24}$ & -1.09 & 3.94 & 0.05 & 875.59 \\
\hline$\beta_{1}$ & 88.21 & 9.22 & 0.49 & 2153.00 & $\beta_{34}$ & -89.80 & -6.73 & -0.36 & -1519.80 \\
\hline$\beta_{2}$ & 5.90 & -3.95 & -0.16 & -1833.80 & $\beta_{35}$ & -18.71 & 0.84 & -0.05 & -974.25 \\
\hline$\beta_{3}$ & 45.90 & -0.31 & 0.31 & 387.05 & $\beta_{36}$ & -35.70 & -5.37 & -0.13 & -1614.80 \\
\hline$\beta_{4}$ & -8.82 & 0.17 & -0.05 & -123.27 & $\beta_{37}$ & -82.51 & -6.54 & -0.36 & -1835.40 \\
\hline$\beta_{5}$ & -94.82 & -3.25 & -0.24 & -3432.00 & $\beta_{45}$ & -23.28 & -0.21 & 0.03 & -478.55 \\
\hline$\beta_{6}$ & -25.99 & -1.60 & -0.04 & -1325.90 & $\beta_{46}$ & -68.08 & -4.40 & -0.38 & -1346.20 \\
\hline$\beta_{7}$ & -119.93 & -5.28 & -0.29 & -3328.60 & $\beta_{47}$ & -1.05 & -0.88 & -0.03 & -127.80 \\
\hline$\beta_{12}$ & 54.79 & 3.38 & 0.29 & 954.11 & $\beta_{56}$ & -3.70 & -1.04 & -0.06 & -361.38 \\
\hline$\beta_{13}$ & 79.63 & 3.44 & 0.28 & 3298.30 & $\beta_{57}$ & 21.57 & 3.03 & 0.05 & 307.36 \\
\hline$\beta_{14}$ & 27.94 & 2.92 & 0.04 & 348.44 & $\beta_{67}$ & -49.77 & -0.33 & -0.17 & -950.54 \\
\hline$\beta_{15}$ & -6.05 & 2.17 & 0.08 & -133.11 & $\beta_{11}$ & 26.60 & 3.10 & 0.12 & 2396.60 \\
\hline$\beta_{16}$ & -40.35 & -1.55 & -0.14 & -961.18 & $\beta_{22}$ & 92.68 & 7.11 & 0.52 & 2413.60 \\
\hline$\beta_{17}$ & -15.72 & -4.56 & -0.08 & 8.54 & $\beta_{33}$ & 21.39 & 3.18 & 0.08 & 1185.40 \\
\hline$\beta_{23}$ & 100.92 & 8.77 & 0.61 & 546.14 & $\beta_{44}$ & -34.37 & -0.72 & -0.05 & 214.72 \\
\hline$\beta_{24}$ & 3.85 & 0.70 & 0.17 & 612.30 & $\beta_{55}$ & -82.66 & -5.38 & -0.18 & 607.61 \\
\hline$\beta_{25}$ & 36.31 & 5.48 & 0.13 & -77.78 & $\beta_{66}$ & -47.69 & -1.28 & -0.14 & -670.30 \\
\hline$\beta_{26}$ & 33.77 & 0.17 & 0.09 & 304.32 & $\beta_{77}$ & 40.25 & 1.77 & 0.29 & 3894.70 \\
\hline & & & & & & & & \\
\hline
\end{tabular}

beginning of the neural network processing, and they pass the data over to adjacent neurons. Weights indicate contribution of the input data from the preceding layer to neurons situated in the next layer. The sum function calculates joint outcome of inputs and weights (net input that approaches adjacent neuron). The activation function is the net input processing function obtained from the sum function, and it determines the neuron output.

\subsubsection{Back-propagation algorithm}

According to Lippman [22], the multi-layer back-propagation network is the most popular ANN paradigm. It is use quite frequently because of its efficient generalization capabilities. In general, the neural network processing consists of two distinct phases: training phase and testing phase.

ANNs have the ability of achieving a favourable level of generalization from the patterns on which they have been trained [23]. Training incorporates processing the neural network with a set of known input-output data. Back-propagation neural networks generally consist of layers with neurons: an input, an output, and one or more hidden layers. The learning process is continued in the output layer, where the error between the network outputs and desired outputs is calculated, and then propagated back to the network with updated weights in the direction in which the performance function decreases most rapidly [24]. All the networks were trained using the LevenbergMarquardt algorithm. The training was stopped when any of these conditions was met:
- Maximum number of 10,000 epochs was reached (MAX_EPOCHS)

- MSE was minimized to within $1 \%$ of the variance of the output data being modelled (MIN_MSE)

- Performance gradient of the Levenberg-Marquardt algorithm fell below 1e-7 (MIN_GRAD)

- Adaptive momentum value of the Levenberg-Marquardt algorithm exceeded 1e10 (MAX_MU).

When the network has been trained, it can be tested on a set of new input and output data that have not been used in the training process.

\subsubsection{Number of hidden neurons}

Random selection of a number of hidden neurons might cause either over fitting or under fitting of prediction models [25]. This concern arises because the network corresponds to the data so closely that the ability for generalization over the test data can be lost.

The number of hidden neurons greatly influences the neural network stability as the latter is estimated via error (minimum error reflects better stability). The excessive number of hidden neurons will cause over fitting in which case neural networks will overestimate complexity of the target problem. Consequently, determination of a proper number of hidden neurons to prevent over fitting is critical for solving prediction problems, with stable generalization capability and the lowest possible deviation. The number of hidden neurons was determined using proposals provided by 15 researchers [25-27] who tested and proposed 
various methodologies. These empirical criteria for the number of hidden neurons in the first hidden layer are presented in Table 4.

The results of 15 equations from Table 4 are presented and summarized in Figure 6 according to the number of input neurons (Table 1: F1-F7, $\mathrm{N}_{\mathrm{i}}=7$ because of 7 components of concrete), and number of outputs (01-04, although there are 4 concrete properties $\mathrm{N}_{0}=1$ because of the accuracy of neural network processing).

Table 4. Empirical criteria for the number of hidden neurons

\begin{tabular}{|c|c|c|c|}
\hline No. & Method & $\mathbf{N}_{\mathrm{h}}$ & Summarized in \\
\hline 1. & Neville (1986) & $0.75 \cdot \mathrm{N}_{\mathrm{i}}$ & (Ozturan, 2008) \\
\hline 2. & Neville (1986) & $2 \cdot \mathrm{N}_{\mathrm{i}}+1$ & (Ozturan, 2008) \\
\hline 3. & Hecht-Nielsen (1987) & $\leq 2 \cdot N_{i}$ & Sonmez, 2006 \\
\hline 4. & Hush (1989) & $3 \cdot \mathrm{N}_{\mathrm{i}}$ & Sonmez, 2006 \\
\hline 5. & Popovics (1990) & $\left(\mathrm{N}_{\mathrm{i}}+\mathrm{N}_{0}\right) / 2$ & (Ozturan, 2008) \\
\hline 6. & Gallant (1993) & $2 \cdot \mathrm{N}_{\mathrm{i}}$ & (Ozturan, 2008) \\
\hline 7. & Wang (1994) & $2 \cdot N_{i} / 3$ & Sonmez, 2006. \\
\hline 8. & Masters (1994) & $\left(\mathrm{N}_{\mathrm{i}}+\mathrm{N}_{0}\right)^{1 / 2}$ & Sonmez, 2006. \\
\hline 9. & Li (1995) & $\left(\left(1+8 N_{i}\right)^{1 / 2}-1\right) / 2$ & (Sheela, 2013) \\
\hline 10. & Tamura (1997) & $N_{i}+1$ & (Sheela, 2013) \\
\hline 11. & Lai (1997) & $\mathrm{N}_{\mathrm{i}}$ & (Ozturan, 2008) \\
\hline 12. & Nagendra (1998) & $\mathrm{N}_{\mathrm{i}}+\mathrm{N}_{0}$ & (Ozturan, 2008) \\
\hline 13. & Zhang (2003) & $2^{\mathrm{Ni} / \mathrm{n}+1}$ & (Sheela, 2013) \\
\hline 14. & Shibata (2009) & $\left(N_{i} \cdot N_{0}\right)^{1 / 2}$ & (Sheela, 2013) \\
\hline 15. & Sheela (2013) & $\left(4 N_{i}^{2}+3\right) /\left(N_{i}^{2}-8\right)$ & (Sheela, 2013) \\
\hline
\end{tabular}

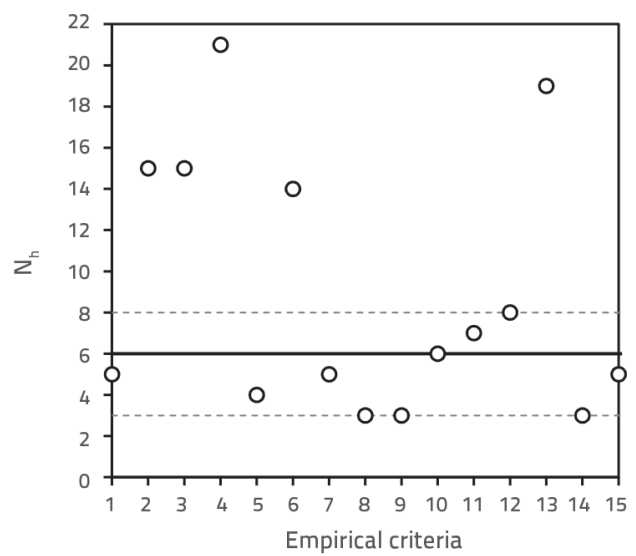

Figure 6. Number of hidden neurons for $N_{i}=7, N_{0}=1$

\subsubsection{Neural network model and parameters}

The ANN model presented in this research has seven neurons in the input layer and one neuron in the output layer as shown in Figure 7. The parameters for input layer were: cement (F1), v/C (F2), water reducing admixture (F3), CT 0-4 (F4), CT 4-16 (F5), CB 0-4 (F6) and CB 4-16 (F7). The output neural network layer consists of four material properties: density (01-N), compressive strength (O2-N), flexural strength (O3-N), and static modulus of elasticity (O4-N) (only one output at the time was applied under network processing).

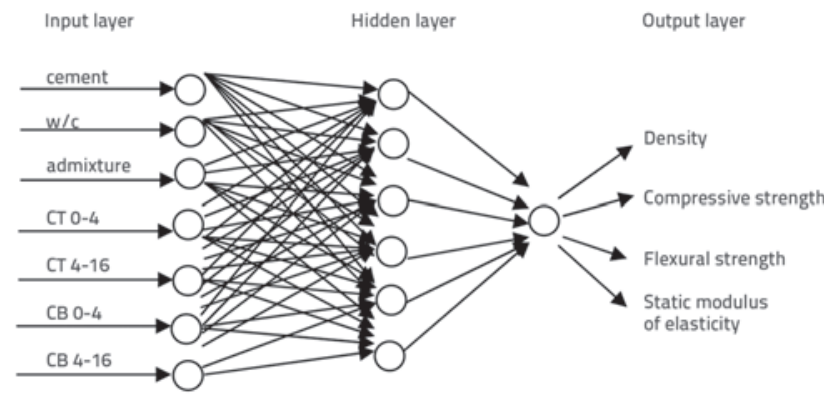

Figure 7. Structure of ANN network: single hidden layer with six hidden neurons

The range of input parameters is shown in Table 5. One hidden layer with three, six, and eight neurons is used in the multilayer neural network architecture, as presented in Figure 7. Because of minimum absolute percentage error values for training and testing sets, only results for six neurons in a hidden layer are presented in this study.

The performance of an ANN model primarily depends on the network architecture and parameter settings. The values of parameters used in the neural network model are given in Table 6.

A total of 62 experiments were trained and tested by means of ANNs. Among 62 experiment sets, 50 sets were randomly chosen as a training set, while the remaining 12 data were used for testing the results.

Table 5. Range of input parameters in ANN models

\begin{tabular}{|c|c|}
\hline Inputs & Range \\
\hline Cement $[\mathrm{kg}]$ & $300-500$ \\
\hline w/c ratio & $0.4-0.6$ \\
\hline Water reducing admixture & $0-1$ \\
\hline CT 0-4 & $0-50$ \\
\hline CT 4-16 & $0-50$ \\
\hline CB 0-4 & $0-50$ \\
\hline CB 4-16 & $0-50$ \\
\hline
\end{tabular}

Table 6. Neural network parameters used in ANN model

\begin{tabular}{|c|c|}
\hline Parameters & ANN \\
\hline Number of input layer units & 7 \\
\hline Number of hidden layers & 6 \\
\hline Number of hidden layer units & 1 \\
\hline Number of output layer units & 0.01 \\
\hline Learning rate & 0 \\
\hline Performance goal & 10000 \\
\hline Maximum number of epochs & \\
\hline
\end{tabular}


Table 7. The range of experimental output parameters in ANN models

\begin{tabular}{|c|c|c|c|c|c|c|}
\hline Symbol & Parameter & Unit & Minimum & Maximum & Standard deviation & Mean \\
\hline 01 & Density & $\mathrm{kg} / \mathrm{m}^{3}$ & 1698.84 & 2450.27 & 171.06 & 2047.25 \\
\hline 02 & Compressive strength & $\mathrm{N} / \mathrm{mm}^{2}$ & 8.70 & 61.75 & 12.05 & 26.42 \\
\hline 03 & Flexural strength & $\mathrm{N} / \mathrm{mm}^{2}$ & 2.31 & 8.84 & 1.49 & 4.88 \\
\hline 04 & Modulus of elasticity & $\mathrm{N} / \mathrm{mm}^{2}$ & 9852.82 & 31995.86 & 5133.65 & 18373.03 \\
\hline
\end{tabular}

In this study, the Matlab ANN toolbox [28] is used for ANN applications. All the networks were trained using LevenbergMarquardt algorithm with "log-sigmoid "transfer functions in between first (input) and second (hidden) layers and 'linear' transfer function between the second and third layers (output).

\subsubsection{Performance evaluation methods}

\begin{tabular}{|c|c|c|c|c|c|c|c|}
\hline $01-\mathrm{N}$ & 0,95 & 0,95 & 0,87 & 0,87 & 1,00 & 0,87 & 0,96 \\
\hline $02-\mathrm{N}$ & 1,00 & 0,93 & 0,83 & 0,83 & 0,83 & 0,83 & 0,89 \\
\hline $03-\mathrm{N}$ & 1,00 & 0,96 & 0,85 & 0,85 & 0,85 & 0,85 & 0,90 \\
\hline & 0,79 & 0,73 & 0,73 & 0,73 & 0,86 & 0,73 & 1,00 \\
\hline & F1 & F2 & F3 & F4 & F5 & F6 & F7 \\
\hline
\end{tabular}

Five different statistical performance

Figure 8. Sensitivity analysis results

measures are used in order to evaluate effectiveness of each network and its ability to make accurate predictions. The following evaluation measures were used for the accuracy of the proposed learning models:

a) Mean absolute error (MAE) - is a quantity used to measure how close predictions are to the known outputs:

MAE $=\frac{1}{n} \sum_{i=1}^{n}\left|y-y^{\prime}\right|$

where $y^{\prime}$ is the predicted value; $y$ is the actual value; and $\mathrm{n}$ is the number of data samples.

b) Root mean square error:

RMSE $=\sqrt{\frac{1}{n} \sum_{i=1}^{n}\left(y^{\prime}-y\right)^{2}}$

c) Mean absolute percentage error:

MAPE $=\frac{1}{n} \sum_{i=1}^{n}\left|\frac{y-y^{\prime}}{y}\right|$

d) Coefficient of correlation:

$R=\frac{\sum_{i=1}^{n}\left((y-\bar{y}) \cdot\left(y^{\prime}-\bar{y}^{\prime}\right)\right)}{\sqrt{\sum_{i=1}^{n}(y-\bar{y})^{2} \cdot \sum_{i=1}^{n}\left(y^{\prime}-\bar{y}^{\prime}\right)}}$

where $y^{\prime}$ is the mean predicted value; $y$ is the mean actual value. e) Nash-Sutcliffe efficiency:

$$
E=1-\frac{\sum_{i=1}^{n}\left(y-y^{\prime}\right)^{2}}{\sum_{i=1}^{n}(y-\bar{y})^{2}}
$$

A lower value of MAE, RMSE, MAPE with higher values of $R$ and E above 0.90 illustrates good efficiency and predictability of the model.

\subsubsection{Sensitivity analysis}

Complex relationships between basic concrete components $F_{1, \ldots, 7}$ and material properties as target output in ANN can be defined by sensitivity analysis. The forward stepwise sensitivity analysis method was applied in this paper in order to identify the most significant input-output relations.

The forward stepwise method estimates the change in the root mean square error of the network by sequentially adding input neurons to the neural network (rebuilding neural network every time at each step). The resulting change in the RMSE for each variable inclusion illustrates the relative importance of the input variables with regard to output results. In sensitivity analysis, RMSE presents an error and importance of the variable for the required output data. The RMSE, as presented in Figure 8., is normalized to values ranging from 0 to 1 (where 0 stands for minimum RMSE). Higher value indicates higher importance of the input variable. According to sensitivity analysis results, all inputs are very important and generally have high influence on all four outputs. Consequently, all input data will be included in further analysis. 

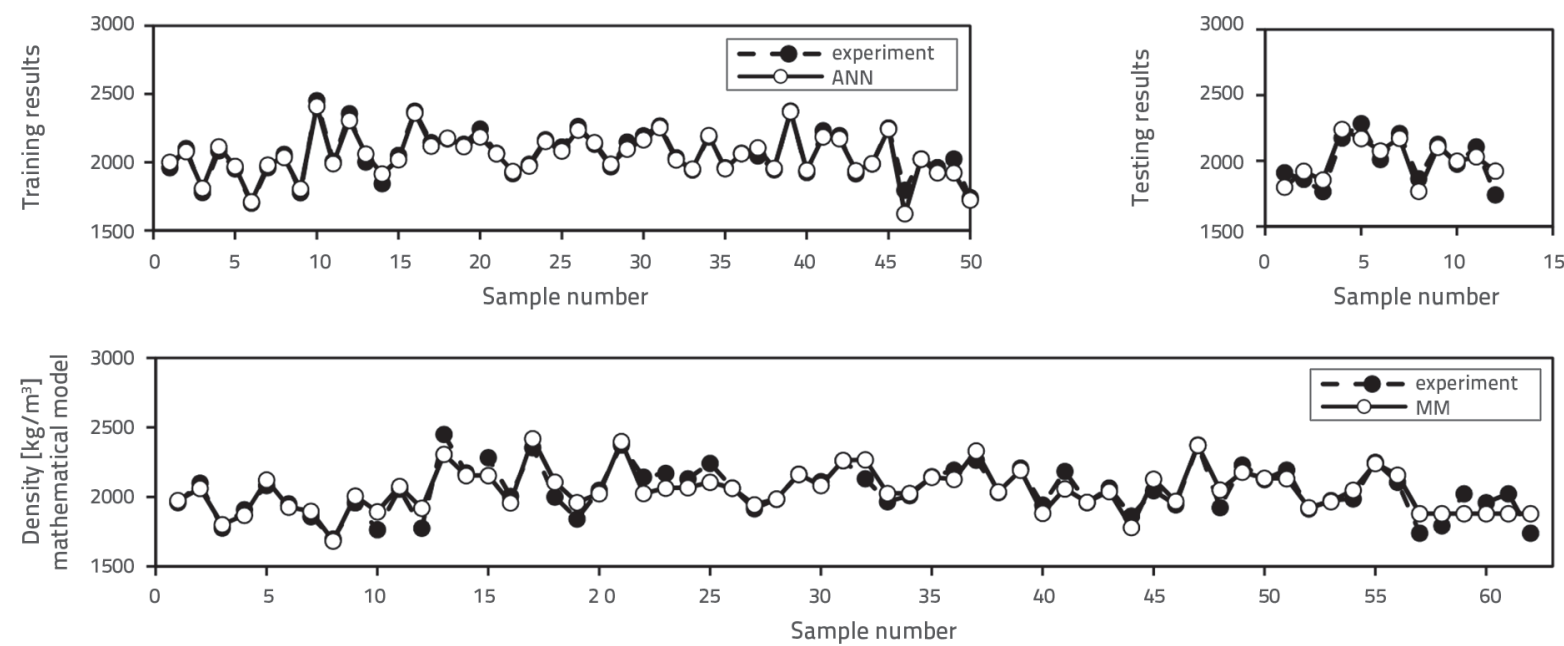

Figure 9. ANN and MM results for output 1

Table 8. Statistical performance of ANN and MM models for output 1

\begin{tabular}{|c|c|c|c|c|c|}
\hline Model & MAE $\left[\mathrm{kg} / \mathrm{m}^{3}\right]$ & RMSE $\left[\mathrm{kg} / \mathrm{m}^{3}\right]$ & MAPE $[\%]$ & R & E \\
\hline ANN & 37.694 & 2.571 & 1.897 & 0.999 & 0.999 \\
\hline MM & 58.645 & 0.015 & 2.910 & 0.999 & 0.998 \\
\hline
\end{tabular}
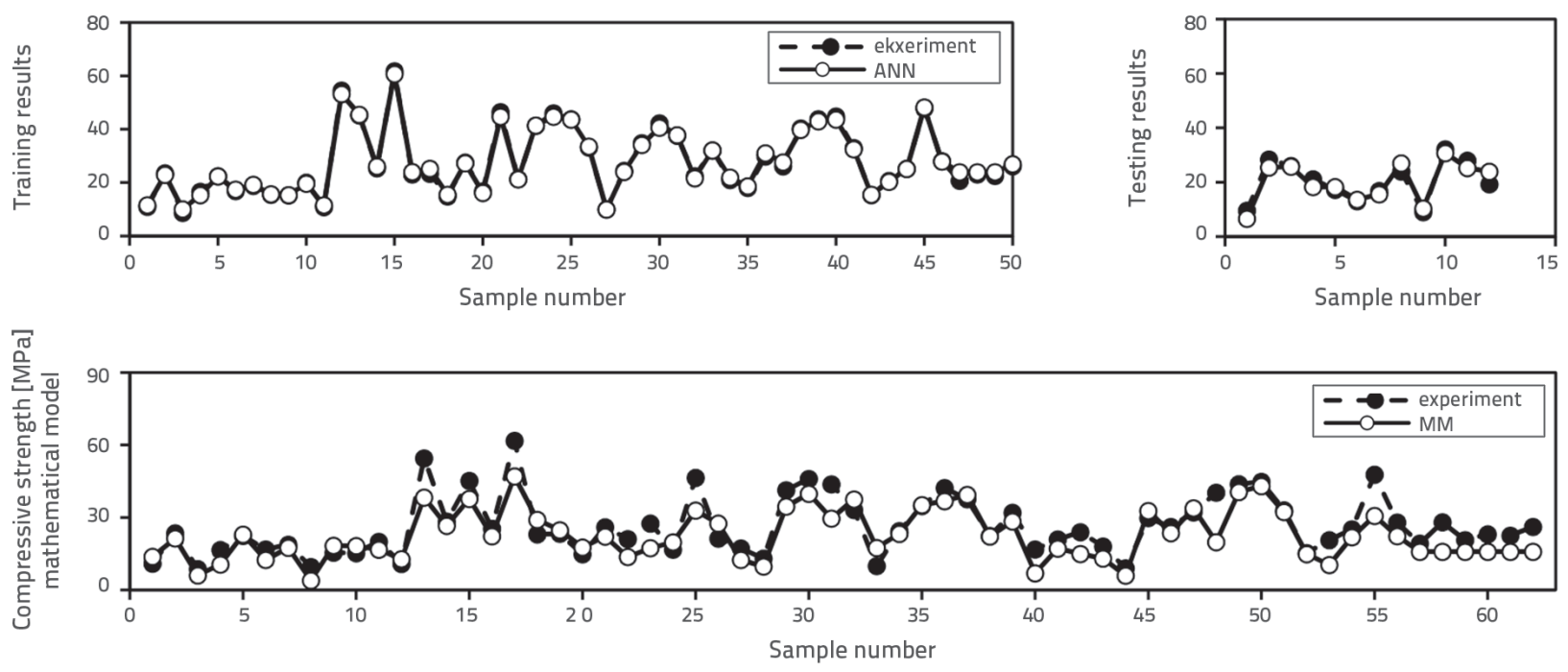

Figure 10. ANN and MM results for output 2

Table 9. Statistical performance of ANN and MM models for output 2

\begin{tabular}{|c|c|c|c|c|c|}
\hline Model & MAE $\left[\mathrm{kg} / \mathrm{m}^{3}\right]$ & RMSE $\left[\mathrm{kg} / \mathrm{m}^{3}\right]$ & MAPE $[\%]$ & R & E \\
\hline ANN & 0.974 & 0.075 & 4.679 & 0.998 & 0.997 \\
\hline MM & 5.469 & 1.970 & 22.250 & 0.973 & 0.931 \\
\hline
\end{tabular}

\section{Results and discussion}

The Artificial Neural Network (ANN) and mathematical model (MM) are tested in this study as an alternative to classic experimental tests for simulating material properties in concrete containing crushed brick and roof tile aggregate. The results obtained are evaluated through comparison of MM and ANN model values.

\subsection{Output 1 - Density}

Figure 9. shows predicted density of concrete with CBT for both 
training and testing sets of the ANN and MM models. The results clearly show that values predicted with ANN and MM models are highly consistent with experimental results for most of the samples. The MAE, RMSE, MAPE, R, and E values for both modelling techniques, ANN and MM, are given in Table 8. It can be seen that the MM model has the smallest RMSE $\left(0.015 \mathrm{~kg} / \mathrm{m}^{3}\right)$, but the ANN model has the smallest MAE and MAPE, and the highest $E$ (0.999). However, it should be noted that the modelling results are exceptionally accurate. Therefore, there is no doubt regarding accuracy of prediction performances of MM and ANN models for density of concrete with CBT.

\subsection{Output 2 - Compressive strength}

The MM model resulted in lower prediction accuracy and higher residuals compared to ANN, Figure 10. Although the MM model provided similar average values of correlation coefficient and NashSutcliffe efficiency when compared to ANN model, it was unable to capture smaller errors (MAPE of $22.25 \%$ ), as shown in Table 9.

In contrast, a fairly high predictability was achieved with the ANN model, with an R and $E$ of 0.99, and a low root mean square error (RMSE) together with low MAPE, indicating a high capacity to simulate the compressive strength of concrete containing crushed brick and roof tile aggregate.

\subsection{Output 3 - Flexural strength}

According to the ANN and MM model predictions, the relationships between experimental and modelled output values are well defined, as shown in Figure 11. In addition, statistical measures accounted for maximum $11 \%$ of absolute errors. Quite high correlation was detected between experimental and modelled values: the correlation coefficient between experimental flexural strength and ANN flexural strength amounted to $\mathrm{R}=0.98$ and $\mathrm{E}=0.96$, i.e. the ANN deviation was smaller by $9 \%$ and $18 \%$ compared to the MM model.

These results show that the ANN model developed for flexural strength exhibits better performance in simulating predicted values compared to mathematical model.

\subsection{Output 4 - Modulus of elasticity}

Results for output 4 show prediction performances for two learning prediction-based models, ANN and MM, for the modulus of elasticity. All results obtained by experimental studies and predicted by training and testing ANN and MM models are given in Figure 12. As can be seen in Figure 11, the values obtained by training and testing ANN and MM models are very close to experimental values. These results show that both models can competently be used for making generalisations between input and output variables, with efficient predictions.

The statistical modelling performance for both models is shown in Table 11. The MM model exhibits the lowest error rate at $\mathrm{RMSE}=7.05 \mathrm{~N} / \mathrm{mm}^{2}$. Overall, the MM model for the modulus of elasticity achieved good outcomes in terms of overall statistical performance. Comparison of five statistical measures showed that the ANN prediction model generally performs better than the MM, with good performance and lower error values.
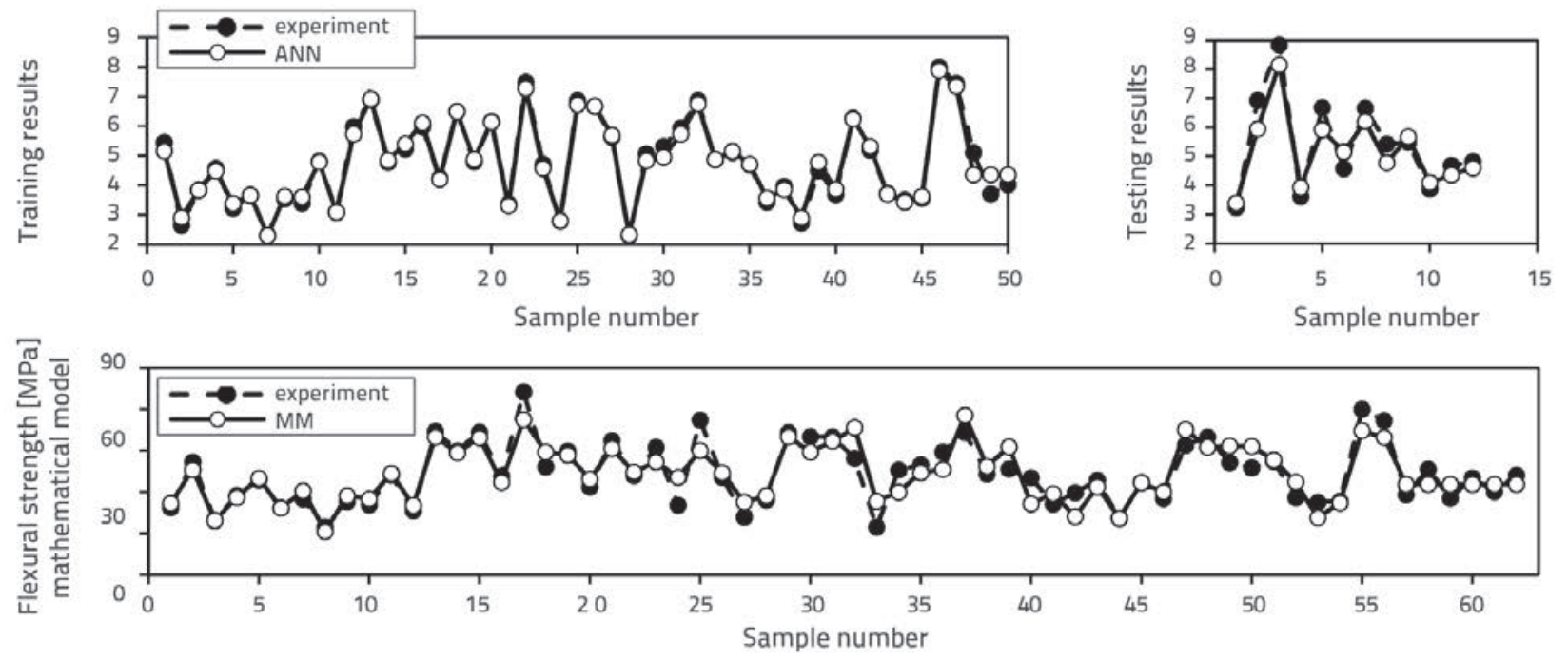

Figure 11. ANN and MM results for output 3

Table 10. Statistical performance of ANN and MM models for output 3

\begin{tabular}{|c|c|c|c|c|c|}
\hline Model & MAE $\left[\mathrm{kg} / \mathrm{m}^{3}\right]$ & RMSE $\left[\mathrm{kg} / \mathrm{m}^{3}\right]$ & MAPE $[\%]$ & $\mathbf{R}$ & $\mathbf{E}$ \\
\hline ANN & 0.199 & 0.2087 & 4.069 & 0.979 & 0.960 \\
\hline MM & 0.5275 & 0.0823 & 11.28 & 0.891 & 0.798 \\
\hline
\end{tabular}



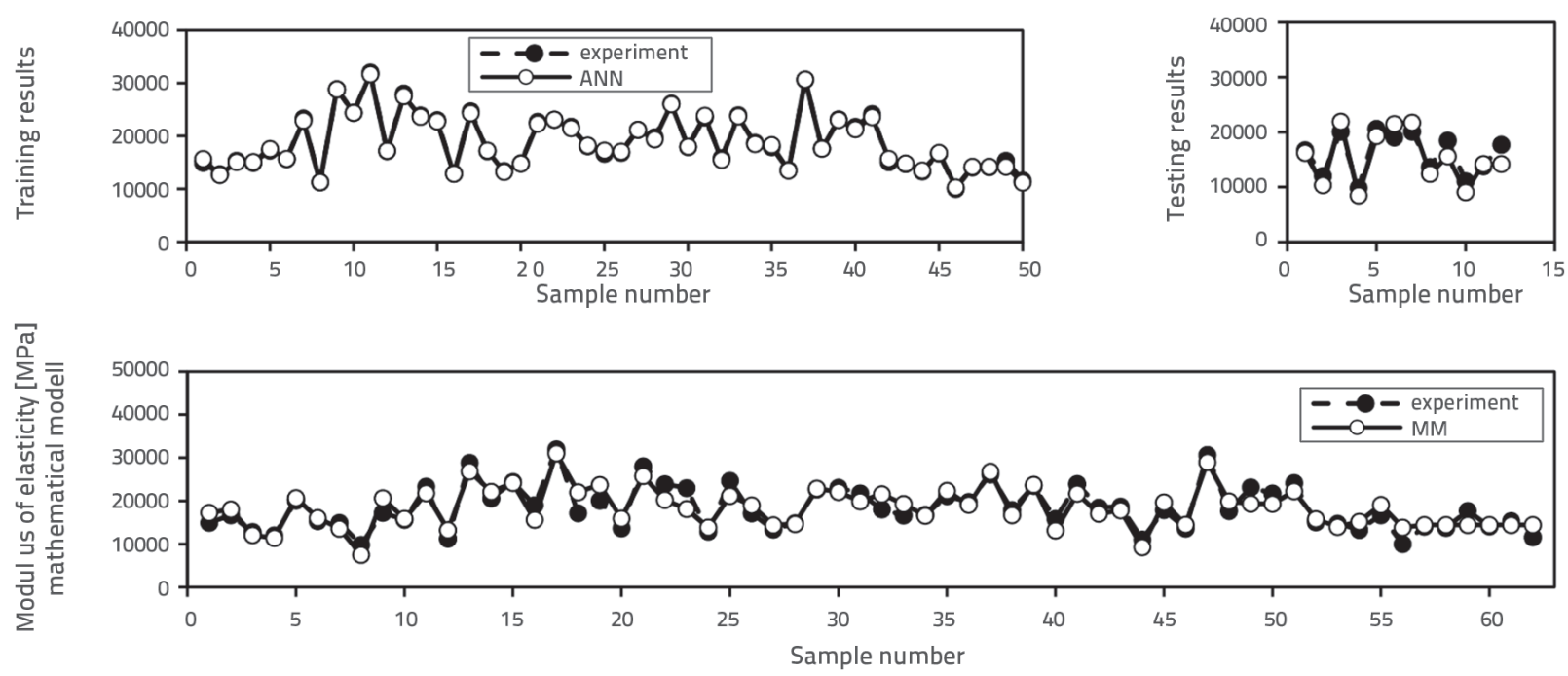

Figure 12. ANN and MM results for output 4

Table 11. Statistical performance of ANN and MM models for output 4

\begin{tabular}{|c|c|c|c|c|c|}
\hline Model & MAE $\left[\mathrm{kg} / \mathrm{m}^{3}\right]$ & RMSE $\left[\mathrm{kg} / \mathrm{m}^{3}\right]$ & MAPE $[\%]$ & R & E \\
\hline ANN & 538.286 & 13.298 & 3.288 & 0.986 & 0.969 \\
\hline MM & 1759.551 & 7.047 & 10.206 & 0.909 & 0.826 \\
\hline
\end{tabular}

\section{Conclusion}

The objective of this study was to make a comprehensive comparison of various prediction techniques used separately for simulating material properties of concrete containing the crushed brick and roof tile aggregate that was previously experimentally examined.

Two individual learning techniques (ANN and MM) were used to develop the prediction models. When compared to experimental results for density, compressive and flexural strength, and modulus of elasticity, both models were found to be capable of generalizing between input and output variables with reliable predictions. On an average, MM model performed the best in terms of RMSE (Outputs 1, 3 and 4). However, the ANN model exhibited lower error rates for another four performance measures, and this for all four outputs.
The contribution of this paper lies in broadening knowledge base in this area, by proposing and checking techniques for simulating material properties of concrete with recycled aggregate. These models can be used in cases when there are too many inputs and properties that need to be known or defined within a restricted period of time. These methods also contribute to a remarkable reduction in computational time and money savings compared to experimental tests, without any significant loss in accuracy. Statistical measures used to evaluate performance of the models showed that both approaches can effectively be used for making reliable predictions, although the artificial neural networks model resulted in lower deviations, and so it can be regarded as a powerful tool for predicting material properties of recycled concrete in the considered range of input values.

\section{REFERENCES}

[1] Cachim, P.B.: Mechanical properties of brick aggregate concrete, Construction and Building Materials, 23 (2009), pp. 1292-1297, https://doi.org/10.1016/j.conbuildmat.2008.07.023

[2] Debieb, F., Kenai, S.: The use of coarse and fine crushed bricks as aggregate in concrete. Construction and Building Materials, 22 (2008), pp. 886-893, https://doi.org/10.1016/j. conbuildmat.2006.12.013

[3] Miličević, I.: Fire resistance of concrete with crushed bricks and roof tiles, PhD Thesis, Faculty of Civil Engineering Osijek, University J.J. Strossmayer Osijek, 2014.

[4] Duan, Z.H., Kou, S.C., Poon C.S.Prediction of compressive strength of recycled aggregate concrete using artificial neural networks, Construction and Building Materials, 40 (2013), pp. 1200-1206, https://doi.org/10.1016/j.conbuildmat.2012.04.063

[5] Deshpande, N., Londhe, S., Kulkarni, S.: Modeling compressive strength of recycled aggregate concrete by Artificial Neural Network, Model Tree and Non-linear Regression, International Journal of Sustainable Built Environment, 3 (2014), pp. 187-198, https://doi.org/10.1016/j.ijsbe.2014.12.002 
[6] Dantas., A.T.A., Batista Leite, M., de Jesus Nagahama, K.:Prediction of compressive strength of concrete containing construction and demolition waste using artificial neural networks. Construction and Building Materials, 38 (2013), pp. 717-722, https://doi. org/10.1016/j.conbuildmat.2012.09.026

[7] Berredo, R.C., Canha, L.N., Ekel, P.Ya., Ferreira, L.C.A., Maciel, M.V.C.: Experimental Design and Models of Power System Optimization and Control, WSEAS Transactions on Systems and Control, 3 (2008) 1, pp. 40-49, 2008.

[8] Lazić, Lj. and Mastorakis, N.E.: Integrated Intelligent Modeling, Simulation and Design of Experiments for Software Testing Process, Latest Trends on Computers (Volume II), $14^{\text {th }}$ International Conference on Computers, pp. 555-567, 2010.

[9] Briano, E., Caballini, C., Giribone, P., Revetria, R.: Design of Experiment and Montecarlo Simulation as Support for Gas Turbine Power Plant Availability Estimation, Proceedings of the $12^{\text {th }}$ WSEAS International Conference on Automatic Control, Modelling \& Simulation, pp. 223-230, 2010.

[10] Montgomery, D.C.: Analysis of Experiments (5 $5^{\text {th }}$ ed.) John Wiley \& Sons, Inc, 2001.

[11] Watson, D.F.: Contouring: A Guide to the Analysis and Display of Spatial Data, Pergamon Press, New York, 1992.

[12] Toledo Filhoa, R.D., Gonçalvesb, J.P., Americanoc, B.B., Fairbairna, E.M.R.: Potential for use of crushed waste calcined-clay brick as a supplementary cementitious material in Brazil, Cement and Concrete Research, 37 (2007) 9, pp. 1357-1365, https://doi. org/10.1016/j.cemconres.2007.06.005.

[13] Bökea, H., Akkurtb, S., İpekoğlua, B., Uğurlua, E.:Characteristics of brick used as aggregate in historic brick-lime mortars and plasters, Cement and Concrete Research, 36 (2006) 6, pp. 1115 1122, https://doi.org/10.1016/j.cemconres.2006.03.011

[14] Khatib, J.M.: Properties of concrete incorporating fine recycled aggregate. Cement and Concrete Research, 35 (2005), pp. 763769, https://doi.org/10.1016/j.cemconres.2004.06.017

[15] Khalaf, F.M.: Using Crushed Clay Brick as Aggregate in Concrete. Journal of Materials in Civil Engineering, 18 (2006), pp. 518-526, https://doi.org/10.1061/(ASCE)0899-1561(2006)18:4(518)

[16] Tam, V.W.Y., Gao, X.F., Tam, C.M.: Microstructural analysis of recycled aggregate concrete produced from two-stage mixing approach, Cement and Concrete Research, 35 (2005), pp. 11951203, https://doi.org/10.1016/j.cemconres.2004.10.025
[17] Hansen. T.C.: Recycling of demolished concrete and masonry. RILEM Rep.6., London: E\&FN Spon.1992.

[18] Miličević, I., Štirmer, N., Bjegović, D.: Optimizing the Concrete Mixture made with Recycled Aggregate Using Experiment Design, Proceedings of Recent advances in fluid mechanics and heat \& mass transfer, Florence, Italy : WSEAS Press, pp. 110-115, 2011.

[19] Miličević, I., Štirmer, N., Bjegović, D.: Optimization of concrete mixtures made with crushed clay bricks and roof tiles, Magazine of Concrete Research, 67 (2015) 3, pp. 109-120, https://doi. org/10.1680/macr.14.00175

[20] Malešev, M., Radonjanin, V., Lukić, I., Bulatović, V.: The Effect of Aggregate, Type and Quantity of Cement on Modulus of Elasticity of Lightweight Aggregate Concrete. Arabian Journal of Science and Engineering, 39 (2013), pp. 705-711, https://doi.org/10.1007/ s13369-013-0702-2

[21] Haykin, S.: Neural Networks: A Comprehensive Foundation, (2nd ed.), Pretince Hall, 1999.

[22] Lippman, R.: An introduction to computing with neural nets, IEEE ASSP Mag., 4 (1987), pp. 4-22, https://doi.org/10.1109/ MASSP.1987.1165576

[23] Bilgehan, M. and Turgut, P.:The use of neural networks in concrete compressive strength estimation, Computers and Concrete, 7 (2010) 3, pp. 271-283, https://doi.org/10.12989/ cac.2010.7.3.271

[24] Kewalramani, M.A. and Gupta, R.: Concrete compressive strength prediction using ultrasonic pulse velocity through artificial neural networks, Automat. Constr., 15 (2006), pp. 374-379, https://doi. org/10.1016/j.autcon.2005.07.003

[25] Sheela, G.K., Deepa, S.N.: Review on Methods to Fix Number of Hidden Neurons in Neural Networks, Mathematical Problems in Engineering, Article ID 425740, pp. 11, 2013.

[26] Sonmez, H., Gokceoglu, C., Nefeslioglu, H.A. and Kayabasi, A.: Estimation of rock modulus: for intact rocks with an artificial neural network and for rock masses with a new empirical equation. International Journal of Rock Mechanics and Mining Sciences, 43 (2006), pp. 224-235, https://doi.org/10.1016/j. ijrmms.2005.06.007

[27] Özturan, M., Kutlu, B., Özturan, T.:Comparison of concrete strength prediction, Techniques with artificial neural network approach, Building research journal, 56 (2008) 1, pp. 23-36.

[28] Beale, M.H., Hagan, M.T., Demuth, H.B. Matlab:Neural networks toolbox user guide, Mathworks, 2015. 